\section{AB1127 1 IS SHOULDER INVOLVEMENT IN CLINICALLY SUSPECT ARTHRALGIA AN EARLY FEATURE OF RHEUMATOID ARTHRITIS? -A LONGITUDINAL ULTRASOUND STUDY}

C. Rogier ${ }^{1}$, M. Van der Ven ${ }^{1}$, A. Van der Helm - van Mil ${ }^{1,2}$, P. De Jong ${ }^{1}$. ${ }^{1}$ Erasmus MC, Rheumatology, Rotterdam, Netherlands; ${ }^{2}$ Leiden University Medical Centre (LUMC), Rheumatology, Leiden, Netherlands

Background: Multiple studies have demonstrated that shoulder complaints are frequent in Rheumatoid arthritis (RA). Recently, it has been shown that shoulder involvement is predictive for RA development in patients with undifferentiated arthritis(UA) and its value is comparable to that of small joint involvement. The phase of clinically suspect arthralgia (CSA) precedes the phase of clinically apparent arthritis; in this phase subclinical tenosynovitis of the hands, is associated with the development of RA. Given the similarities in predictive values between the shoulder and small joints in UA, and the predictive value of tenosynovitis in CSA, we hypothesized that subclinical tenosynovitis of the bicep tendon is also associated with RA development. We examined the biceps tendon, since this is the only tendon of the shoulder that is enclosed by a synovial sheath as it passes through the bicipital groove.

Objectives: Therefore, the aim of this study is to examine the predictive value of tenosynovitis of the bicep tendon by ultrasound (US) on developing inflammatory arthritis (IA) in CSA-patients.

Methods: The SONAR (Sonographic evaluation of hands, shoulders and feet in patients presenting with inflammatory arthralgia to identify subclinical arthritis) is a multi-center observational cohort study in which patients were followed for the development of clinically apparent inflammatory arthritis (IA). Visits were done at baseline and 6 monthly thereafter. At baseline a US of both shoulders was made. 1-year follow-up data were used. IA was defined as having an arthritis verified by the treating physician. US abnormalities of (1) the biceps tendon, (2) the glenohumeral joint and (3) the subdeltoid bursa, were assessed for tenosynovitis, arthritis and bursitis.. Reference values for tendon thickness and effusion of the bursa were determined according to Schmidt et al.(1)

Results: A total of 170 patients were included and underwent bilateral ultrasound (US) of the shoulder joint. Shoulder symptoms were infrequent (Table 1). After one year 37 patients developed IA (22\%). ACPA positivity was associated with the development of IA (Table 1). As presented in Table 1, US abnormalities of the shoulder were found but none were associated with IA-development. In particular biceps tenosynovitis was not increased in the patients that developed IA.

Table 1. Baseline characteristics and ultrasound abnormalities at baseline in patients with CSA.

\begin{tabular}{|c|c|c|c|c|}
\hline Baseline characteristics & $\begin{array}{c}\text { All } \\
\text { CSA-patients } \\
n=170\end{array}$ & $\begin{array}{l}\text { CSA-patients } \\
\text { with IA } \\
(n=37)\end{array}$ & $\begin{array}{l}\text { CSA-patients with- } \\
\text { out IA }(n=133)\end{array}$ & $\begin{array}{c}\mathrm{P} \\
\text { value }\end{array}$ \\
\hline Gender, female, n (\%) & $140(82)$ & $30(81)$ & $110(83)$ & 0.82 \\
\hline Age, years, mean (SD) & $45(12)$ & $47(12)$ & $44(12)$ & 0.28 \\
\hline $\begin{array}{l}\text { Symptom duration, weeks median } \\
\text { (IQR) }\end{array}$ & $30(19-43)$ & $37(23-43)$ & $28(19-39)$ & 0.14 \\
\hline TJC44, median (IQR) & $5(3-8)$ & $5(3-8)$ & $5(3-8)$ & 0.81 \\
\hline Shoulder pain, n (\%) & $9(5)$ & $0(0)$ & $9(6.8)$ & 0.10 \\
\hline SJC44, median (IQR) & $0(0-0)$ & $0(0-0)$ & $0(0-0)$ & - \\
\hline ESR, median (IQR) & $10(5-21)$ & $9(5-22)$ & $11(5-21)$ & 0.66 \\
\hline RF-positive, n (\%) & $46(28)$ & $12(34)$ & $34(26)$ & 0.33 \\
\hline $\begin{array}{l}\text { ACPA-positive, n (\%) } \\
\text { US abnormalities } \\
\text { of the shoulder }\end{array}$ & $26(16)$ & $10(29)$ & $16(12)$ & 0.019 \\
\hline $\begin{array}{l}\text { Any US } \\
\text { abnormalities, } n(\%) \\
(n=170)\end{array}$ & $50(29)$ & $8(22)$ & $42(32)$ & 0.24 \\
\hline $\begin{array}{l}\text { Biceps tendon Tenosynovitis, } n(\%) \\
(n=164)\end{array}$ & $19(12)$ & $5(15)$ & $14(11)$ & 0.48 \\
\hline $\begin{array}{l}\text { Biceps tendon thickness, } n(\%) \\
(n=164)\end{array}$ & $6(4)$ & $0(0)$ & $6(5)$ & 0.19 \\
\hline $\begin{array}{l}\text { Subdeltoid bursa effusion, } n(\%) \\
(n=159)\end{array}$ & $29(18)$ & $3(9)$ & $26(21)$ & 0.094 \\
\hline $\begin{array}{l}\text { Effusion joint, } n(\%) \\
(n=157)\end{array}$ & $0(0)$ & $0(0)$ & $0(0)$ & - \\
\hline
\end{tabular}

Abbreviations: IA: Inflammatory Arthritis, TJC44: Tender Joint Count in 44 joints, SCJ44: Swollen Joint Count in 44 joints,, ESR: Erythrocyte sedimentation rate, RF: Rheumatoid Factor, ACPA: Anti-citrullinated Protein Antibody

Conclusion: Subclinical tenosynovitis of the shoulder is not an early feature of RA in patients with CSA.

Reference:

[1] Schmidt WA, Schmidt H, et al. Standard reference values for musculoskeletal ultrasonography. Ann Rheum Dis. 2004 Aug;63(8):988-94.
Acknowledgments: *van der Helm- van Mil and de Jong contributed equal to this study

Disclosure of Interests: None declared

DOI: 10.1136/annrheumdis-2020-eular.1506

\section{AB1128 ULTRASOUND SYNOVITIS AND SQUEEZE TEST: IS THERE A RELATIONSHIP?}

K. Ben Abdelghani ${ }^{1}$, K. Saadaoui ${ }^{1}$, A. Fazaa ${ }^{1}$, S. Miladi ${ }^{1}$, K. Ouenniche ${ }^{1}$, L. Souabni ${ }^{1}$, S. Kassab ${ }^{1}$, S. Chkili ${ }^{1}$, L. Zakraoui ${ }^{1}$, A. Laatar ${ }^{1} .{ }^{1}$ Mongi Slim Hospital, Rheumatology, Marsa, Tunisia

Background: The squeeze test or the Gaenslen's test is an easy and rapid method to identify arthritis in metacarpophalangeal (MCP) and metatarsophalangeal (MTP) joints. It's characterized by tenderness upon lateral compression of MCP or MTP joints. This is a useful clinical exam for the early diagnosis of Rheumatoid Arthritis (RA).

Objectives: The aim of our study is to assess the real value of that test and its association with synovitis.

Methods: A prospective study including RA patients (2010 ACR/EULAR criteria) was conducted at the Rheumatology Department of Mongi Slim Hospital Tunis. US examination was performed by an experimented rheumatologist blinded to clinical data using a machine type Esaote MyLAb 60 with a linear probe of 6-18 MHz. MCP joints were assessed in dorsal longitudinal view, in mode B and Power Doppler.

Synovitis was defined and Flexor digitorum Tenosynovitis was defined according to OMERACT.

A $p<0.05$ was considered statistically significant.

Results: Forty-three cases of RA were included. The mean age was 58.92 years [27 - 81]. The sex ratio was 0.16 . Among our patients, $46.5 \%$ of cases were receiving methotrexate with a mean dose of $15,875 \mathrm{mg} /$ week [7.5 - 22.5]. Corticosteroids were used in $55.8 \%$ of our patients with a mean dose of $8.65 \mathrm{mg} /$ day [2.5 - 30]. Moreover, $23.25 \%$ of the patients were on biologics.

The mean value of morning stiffness was $37 \min [0-150]$, the mean value of the global assessment of the disease by the patient was 5/10 [1 - 8]. The Gaenslen's test was positive bilaterally in $25,6 \%$ of cases, in the right hand and in the left one in respectively $39.5 \%$ and $27.9 \%$ of the patients. Tenosynovitis of the flexors were found clinically in $11.6 \%$ case.

The mean CRP was $29.7 \mathrm{mg} / \mathrm{L}$ [0.2 - 275] and the mean ESR was $65 \mathrm{~mm}$ [3 120]. The mean value of DAS28 and DAS28 8 were respectively $5.20 \pm 1.43$ [2.69 - 9.00] and $4.33 \pm 1.43$ [1.35 - 8.32]. Overall, 430 joints and 430 flexor tendons were assessed by Ultrasound. Ninety-one synovitis were detected with a mean of 2.56 synovitis in MCP per patient [0 - 10]. Flexor tenosynovitis was found in $53.5 \%$ of patients.

A statistically significant correlation was found between the squeeze test and presence of ultrasound synovitis of the MCP whatever the site of the synovitis; on the right side $\left(r=0.507 ; p<10^{-3}\right)$, or the left one $\left(r=0.607 ; p<10^{-3}\right)$ but no correlation between the clinically detected tenosynovitis and the ultrasound tenosynovitis ( $p=0.364$ ). We found a significant correlation between the Gleason test and ultrasound tenosynovitis on both side with $r=0.368$ and $p=0.015$ on the right hand and $r=0.441$ and $p=0.003$ on the left one.

Conclusion: The squeeze test seems to be a very useful and practical clinical examination to easily detect synovitis and aid in the early diagnosis of RA

Disclosure of Interests: None declared

DOI: 10.1136/annrheumdis-2020-eular.6061

\section{AB1129 ULTRASOUND IN PATIENTS WITH CONNECTIVE TISSUE DISEASES AND THEIR IMPACT ON DISEASE MANAGEMENT}

K. Weiß ${ }^{1}$, W. A. Schmidt ${ }^{2}$, A. Krause ${ }^{2}$, V. S. Schäfer ${ }^{3} .{ }^{1}$ Asklepios Nordseeklinik Westerland GmbH, Internal Medicine, Sylt OT Westerland, Germany; ${ }^{2}$ Immanuel Krankenhaus Berlin, Rheumatology and Clinical Immunology, Berlin, Germany; ${ }^{3}$ University Hospital Bonn, Department of Internal Medicine III, Bonn, Germany

Background: Patients with connective tissue diseases (CTD) are often screened for abdominal organ involvement with ultrasound.

Objectives: To analyse the prevalence of routine abdominal ultrasound findings in different CTD entities and their impact on therapeutic decisions.

Methods: Retrospective chart review of all in-patients from a tertiary rheumatological referral center with CTD diagnosis and abdominal ultrasound examination between January 1st 2006 and December 31st 2015. Descriptive statistics were used to describe patient characteristics and frequencies of ultrasound findings. To determine whether findings impacted therapeutic decisions, we analysed if they were discussed in the hospital discharge letter. 